\title{
Localization and upregulation of survivin in cancer health disparities: a clinical perspective
}

This article was published in the following Dove Press journal:

Biologics: Targets and Therapy

9 July 2015

Number of times this article has been viewed

\author{
Salma Khan ${ }^{1,2}$ \\ Heather Ferguson Bennit ${ }^{1,2}$ \\ Malyn May Asuncion \\ Valenzuela ${ }^{1,2}$ \\ David Turay ${ }^{1,3}$ \\ Carlos J Diaz Osterman ${ }^{1,2}$ \\ Ron B Moyron ${ }^{1,2}$ \\ Grace E Esebanmen ${ }^{1,2}$ \\ Arjun Ashok ${ }^{1,2}$ \\ Nathan R Wall ${ }^{1,2}$ \\ 'Department of Biochemistry, ${ }^{2}$ Center \\ for Health Disparities and Molecular \\ Medicine, ${ }^{3}$ Department of Anatomy, \\ Loma Linda University School of \\ Medicine, Loma Linda, CA, USA
}

\begin{abstract}
Survivin is one of the most important members of the inhibitors of apoptosis protein family, as it is expressed in most human cancers but is absent in normal, differentiated tissues. Lending to its importance, survivin has proven associations with apoptosis and cell cycle control, and has more recently been shown to modulate the tumor microenvironment and immune evasion as a result of its extracellular localization. Upregulation of survivin has been found in many cancers including breast, prostate, pancreatic, and hematological malignancies, and it may prove to be associated with the advanced presentation, poorer prognosis, and lower survival rates observed in ethnically diverse populations.
\end{abstract}

Keywords: survivin, cancer, exosomes, health disparity

\section{Introduction}

Cancer is a major public health problem in the United States and the world. Recent epidemiological statistics indicate that cancer will develop in one in three women and one in two men in the US over their lifetime. ${ }^{1}$ The three most common cancers among males are prostate, colorectal, and melanoma of the skin; and among females, breast, uterine corpus, and colorectal. ${ }^{2}$ Although deaths attributed to cancer have declined among both Caucasians and African Americans, the latter continue to suffer a greater burden for each of the most common types of cancer. ${ }^{1}$ This discrepancy recorded among cancer patients from different ethnicities is termed cancer health disparity. The National Cancer Institute defines cancer health disparity as an adverse difference in cancer incidence (new cases), cancer prevalence (all existing cases), cancer death (mortality), cancer survivorship, and burden of cancer or related health conditions that exist among specific population groups. ${ }^{1}$ When investigating the factors that contribute to cancer health disparities, the most obvious are access to health care and socioeconomic status. ${ }^{3-5}$ However, evidence exists that dietary fat can influence carcinogenesis. ${ }^{6}$ In 1982, the US National Academy of Sciences committee on Diet, Nutrition, and Cancer, using both epidemiological and experimental data, concluded that a causal relationship between fat intake and the occurrence of cancer exists. ${ }^{7}$ However, the strongest evidence that environmental factors give rise to an etiology of cancer comes from the studies of cancer incidence in different ethnic populations and their migrations and lifestyle habits. Specifically, the adoption of a Westernized diet appears causal in the significant increase in annual deaths in native Japanese from colon, ${ }^{8}$ breast, ${ }^{9}$ and pancreatic cancers ${ }^{10}$ upon their moving from Japan to the US. In addition, experimental animal studies agree that both specific and nonspecific evidence
Correspondence: Nathan R Wall Department of Basic Sciences, Division of Biochemistry, Center for Health Disparities and Molecular Medicine, Mortensen Hall Room \#I62, Loma Linda University, Loma Linda, CA 92350, USA

Tel +I 9095584000 ext 8I397

Fax + I 9095580177

Email nwall@llu.edu 
exists for the occurrence of cancer being strongly associated with the consumption of a diet high in fat. ${ }^{11}$ Contradictory studies also exist in which lifestyle factors in cancer incidence have been described. Whereas years of smoking and number of cigarettes smoked had a correlation with an increased incidence of pancreatic cancer, there was no correlation with pancreatic cancer and body mass index, physical activity, alcohol, coffee, and green tea consumption. ${ }^{12}$

Early detection is important in cancer discovery, treatment, and survival. In order to better understand cancer incidence and mortality in diverse populations, it has become imperative that we identify and then characterize markers of cancer development and progression to include both pathways and molecular mechanisms associated with these disparities. Given the strong link between cancer incidence, oxidative stress, and diets high in fat, ${ }^{13}$ we must map these associations and identify the survival entities and pathways as potential targets. A long-term goal in health disparities research is to understand how an increase in oxidative stress will ultimately promote cancer cell resistance to therapyinduced death and how to overcome this resistance.

Survivin is an important member of the inhibitors of apoptosis (IAP) protein family because its tumor-specific expression is unique out of all of the human gene products. ${ }^{14}$ Survivin expression is evident during embryonic and fetal development, but not in terminally differentiated tissue. ${ }^{15}$ It is expressed in virtually all of the different types of human cancers (Table 1), making survivin an alluring protein in the study of carcinogenesis. ${ }^{16}$ Survivin is referred to as a bifunctional protein, having essential roles in inhibiting apoptosis and controlling proper cell division. ${ }^{17}$ In our most recent work, we have begun to refer to survivin as a multifunctional protein as it does much more, to include controlling diverse cellular functions, including surveillance checkpoints, suppression of cell death, the regulation of mitosis, and adaptation to unfavorable environments. ${ }^{17,18}$

\section{Localization of survivin}

The multifaceted functionality of survivin is still being intensely scrutinized, and it appears that protein compartmentalization may be important. Survivin has been shown to localize in mitochondria, where it modulates tumor cell apoptosis similar to the Bcl-2 family. ${ }^{19}$ Its localization to the nucleus and cytosol confers its role in mitosis regulation and apoptosis inhibition, respectively. ${ }^{20}$ Furthermore, we have identified the existence of survivin extracellularly, contained in small membrane-bound vesicles known as exosomes (Figure 1), and have shown that the exosome-bound survivin
Table I Influence of survivin on clinical prognosis

\begin{tabular}{|c|c|c|c|}
\hline $\begin{array}{l}\text { Cancer } \\
\text { type }\end{array}$ & $\begin{array}{l}\text { On prognosis/ } \\
\text { staging } \\
\text { of the disease }\end{array}$ & $\begin{array}{l}\text { Survivin } \\
\text { expression }\end{array}$ & Reference \\
\hline $\begin{array}{l}\text { Breast } \\
\text { cancer }\end{array}$ & Good to poor & $\begin{array}{l}\text { Moderate } \\
\text { to high }\end{array}$ & $\begin{array}{l}\text { Kalla Singh et al, } 2010^{66}, \\
\text { Adamkov et al, } 2012^{67}, \\
\text { Rexhepaj et al, } 2010^{68}, \\
\text { Xu et al, } 2012^{69}, \\
\text { Dedić Plavetić et al, } 2013^{70} \text {, } \\
\text { Span et al, } 2006^{71} \text {, Li, } \\
2005^{72} \text {, Boidot et al, } 2009^{74} \text {, } \\
\text { Khan et al, } 2014^{75}\end{array}$ \\
\hline $\begin{array}{l}\text { Prostate } \\
\text { cancer }\end{array}$ & Fair to poor & $\begin{array}{l}\text { Moderate to } \\
\text { high }\end{array}$ & $\begin{array}{l}\text { Zaffaroni et al, } 2005^{80} \text {, } \\
\text { Shariat et al, } 2004^{81} \text {, Koike } \\
\text { et al, } 2008^{82} \text {, Zhang et al, } \\
2009^{83}\end{array}$ \\
\hline $\begin{array}{l}\text { Pancreatic } \\
\text { cancer }\end{array}$ & Poor & High & Xie et al, $2013^{93}$ \\
\hline Leukemia & Good to poor & Low to high & $\begin{array}{l}\text { Fulda, } 2009^{100} \text {, Kamihira } \\
\text { et al, } 200 \mathrm{I}^{102} \text {, Park et al, } \\
201 \mathrm{I}^{104}, \text { Kelly et al, 20I I }{ }^{105}, \\
\text { Troeger et al, 2007 } \\
\text { et al, } 201 \mathrm{I}^{106}, \text { Esh } \\
2012^{108}, \text { Ahner et al, } \\
\text { Morrison et al, } 2012^{110}, \\
\text { Grzybowska-lzydorczyk } \\
\text { et al, } 2010^{112}, \text { Carter et al, } \\
2012^{113}, \text { Small et al, } 2010^{114}\end{array}$ \\
\hline $\begin{array}{l}\text { Other } \\
\text { cancers }\end{array}$ & Good to poor & $\begin{array}{l}\text { Moderate to } \\
\text { high }\end{array}$ & $\begin{array}{l}\text { Waligorska-Stachura et al, } \\
2012^{99}\end{array}$ \\
\hline
\end{tabular}

protein can be secreted by cancer cells to be taken up by surrounding cells, producing a field effect that confers a general stress-survival phenotype. ${ }^{21-23}$ Consistent with survivin's association with unfavorable clinicopathological parameters, extracellular trafficking of survivin throughout the tumor microenvironment could be responsible for augmenting the aggressive status of a tumor, while prohibiting or minimizing therapeutic results. ${ }^{21,24,25}$ This review focuses on the multifaceted roles of survivin in cancer biology, its cellular localization, and its cancer health disparity-specific upregulation, specifically in breast, prostate, pancreas, and hematological cancers.

\section{Nuclear survivin as a cell cycle regulator}

Nuclear survivin is known to be a cell-cycle-associated protein. Investigations of cell division regulation during the depletion of survivin by small interfering (si)RNA demonstrated an increase in mitotic arrest and chromosomal misalignment. Furthermore, this study confirmed that survivin is involved in microtubule assembly and centromere stabilization during mitosis. ${ }^{26}$ Survivin's role in mitosis regulation is associated with its involvement in the chromosomal 


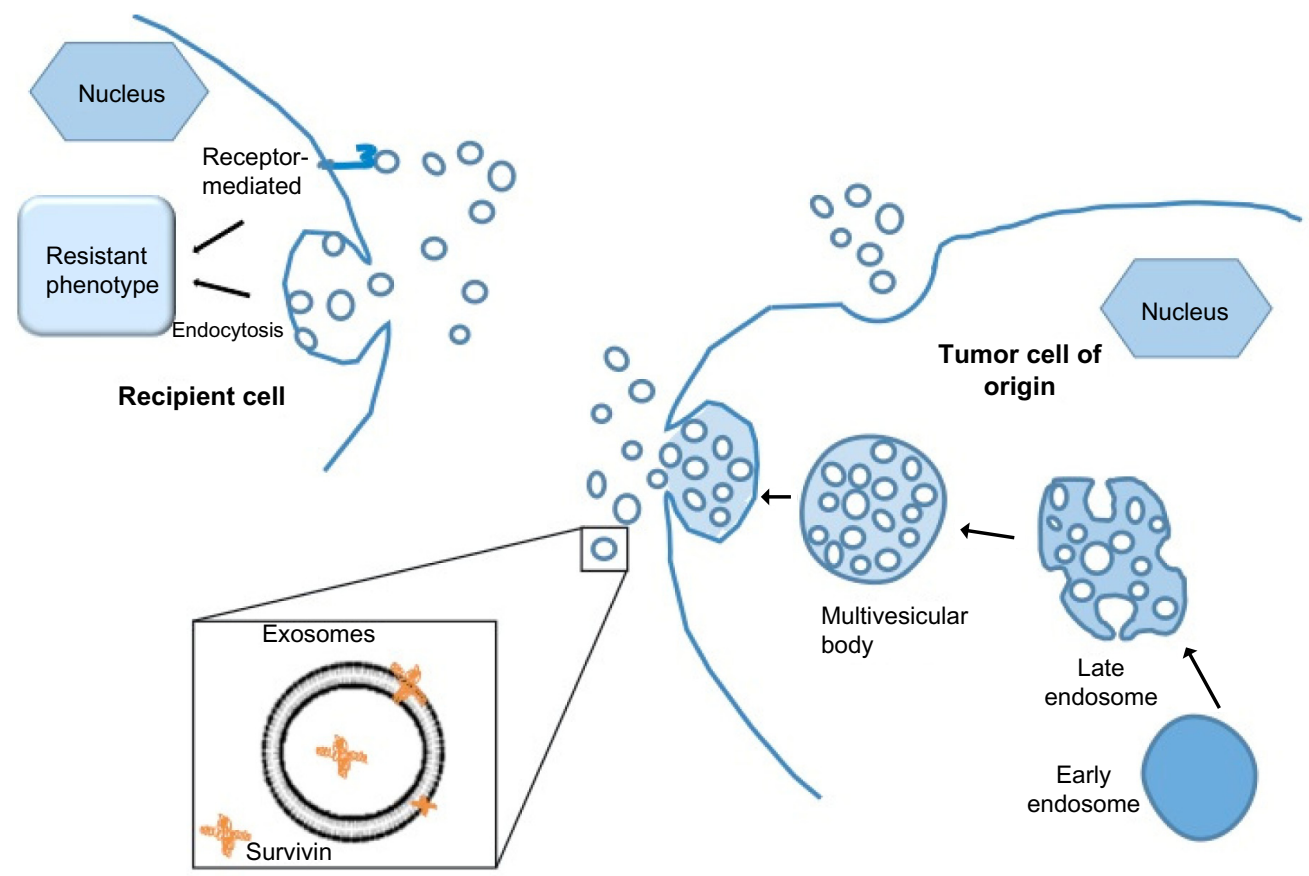

Figure I Exosomes play important roles in intercellular communication.

Notes: A tumor cell communicates with the tumor microenvironment and may be able to affect cancer cell aggressiveness as a result of the protein, RNA, and/or microRNA payload found within. One potentially important protein to the proliferative, invasive, or therapy-resistant nature of the tumor is survivin, which has been found released from cancer cells in exosomes.

packaging complex and its contribution to the formation of the mitotic spindle. ${ }^{27,28}$ IAP family proteins cIAP2 and survivin have been shown to dramatically increase upon exposure to hypoxia. ${ }^{29,30}$ Furthermore, survivin's promoter has been shown to contain three putative HIF-1 binding or response elements. ${ }^{31}$ Nuclear survivin was found to be distinctly involved in the prognosis of different cancers, as will be discussed in our specific cancers section.

\section{Cytoplasmic/mitochondrial survivin as an apoptosis inhibitor}

Survivin's ability to interfere with cellular death pathways appears to reside in the cell's cytoplasm. Survivin localizes to the mitochondria ${ }^{19}$ and therefore may provide, like Bcl-2, a role in mitochondrial stability. Cellular stress was shown to modulate the expression and localization of surviving, with hypoxia-induced survivin found exclusively in the mitochondria. Furthermore, upon apoptotic stimulation, mitochondrial survivin is rapidly released to the cytosol where its cytoprotective effects prevent the activation of the initiator caspase $9 .{ }^{19}$

Early studies showed that survivin and XIAP protected cells from undergoing caspase-dependent apoptosis. Subsequently, in vitro binding experiments showed that survivin, like XIAP and other IAPs, bound to the terminal effector cell death proteases, caspases 3 and 7, but not to initiator caspase $8 .^{32}$ Controversy in the field arose when a study by Banks et $\mathrm{l}^{33}$ showed that survivin did not inhibit caspase 3 activity, and where recombinant survivin failed to decrease recombinant caspase 3 activity in vitro. Current evidence suggests that survivin acts on caspases in an indirect manner by binding to the hepatitis $\mathrm{B} X$-interacting protein (HBXIP) and forming a complex with procaspase 9, inhibiting the apoptosome formation. ${ }^{34}$ This survivin-HBXIP complex, not individual survivin or HBXIP proteins, binds to procaspase 9 and works to prevent recruitment of apoptosis activating factor 1 (Apaf1), thus suppressing intrinsic apoptosis. In addition, survivin binds to and regulates the stability of XIAP, which is a direct caspase 3 and 9 inhibitor. ${ }^{27}$ More specifically, the formation of a survivin-XIAP complex promotes increased XIAP stability, protecting XIAP from proteasomal degradation, resulting in a facilitated inhibition of caspase-dependent cell death. ${ }^{30}$

\section{Extracellular survivin as a modulator of tumor microenvironment}

Survivin has recently been shown to exist in the extracellular space, ${ }^{21}$ via $40-100 \mathrm{~nm}$ membrane vesicles called exosomes. ${ }^{22}$ Various cell types, such as B- and T-lymphocytes, dendritic cells, neurons, intestinal epithelial cells, as well as 
tumor cells, release exosomes. ${ }^{35-38}$ In particular, it has been shown that both human and mouse tumor cells release tumor cell-derived exosomes (TEX) constitutively. ${ }^{39}$ Additionally, specific protein content found both on and within TEX give an indication of their functional and biological roles, and their cell of origin, making TEX excellent biomarkers. ${ }^{40-43}$ Early detection, aggressive determination, and therapeutic efficacy may 1 day be possible through the use of these exosomes and their contents.

Our lab has shown that the extracellular pool of survivin has the ability to cause neighboring cancer cells to increase resistance to therapy, rapidly proliferate, and acquire an increased potential to become invasive in vitro, ${ }^{21}$ providing a protective role to the neighboring tumor cells. ${ }^{22}$ The ability of extracellular survivin to cause these effects in the surrounding cancer cells correlates with the fact that survivin overexpression is observed in virtually every human cancer type. ${ }^{44}$ TEX may also be used as a tool to detect malignant conditions. ${ }^{43}$ Serum taken from cancer patients has an increased level of TEX, ${ }^{45,46}$ which has a positive correlation with the progression of the tumor. ${ }^{22}$ In addition to serum, TEX were shown to be isolated from malignant tumor fluids, urine, ${ }^{47,48}$ ascites fluids, ${ }^{49,50}$ and pleural effusions. ${ }^{40,51} \mathrm{We}$ have recently shown that exosomal survivin may be a useful tool for early detection, diagnosis, and even monitoring of prostate cancer (PCa) progression. ${ }^{52}$ Newly diagnosed and advanced PCa patients with high- or low-grade cancer had significantly higher levels of exosomal survivin compared to control subjects or patients with preinflammatory benign prostatic hyperplasia (BPH). ${ }^{52}$

\section{Survivin in cancer immunity evasion}

Survivin has been ascribed multiple roles not only in malignancy but also in immunity and differentiation. ${ }^{53}$ Survivin has been shown to be essential for T-cell maturation, homeostasis, and proliferation at various stages of development. ${ }^{54}$ It has also been shown to modulate peripheral blood leukocytes when in the extracellular space by binding to leukocytes, thereby inducing molecular processes implicated in the pathogenesis of inflammation. ${ }^{55} \mathrm{On}$ the basis of the literature and our data, survivin may be said to exhibit duplicity in cancer immunity, as it can act as a tumor-associated antigen, or modulate the immune environment to permit tumor growth. ${ }^{53-62}$

Recently, an artificial antigen-presenting cell, developed to study anti-survivin $\mathrm{CD}^{+} \mathrm{T}$-cell responses in cancer patients, was shown to elicit both $\mathrm{Th} 1$ and $\mathrm{Th} 2$ responses against survivin. ${ }^{56}$ The level of avidity was appropriate to recognize tumor cells. ${ }^{56}$ Previously, constructed DNA-peptide complexes (mimovirus) of survivin epitopes have been shown to stimulate strong cytotoxic T-lymphocyte-mediated longterm memory of murine immune response and exact a high antitumor effect in BALB/c mice. ${ }^{57}$ Furthermore, a DNA construct encoding a secreted version of survivin, along with a plasmid coding for murine granulocyte-macrophage colony-stimulating factor as a molecular adjuvant, was observed to elicit humoral responses against survivin in sera collected from mice. ${ }^{57}$ The immunoglobulin G2a antibody was the prevalent antibody subclass, thereby implicating the induction of a Th1-CD4+ cellular response. ${ }^{58}$

We have recently shown that when T-cell cultures were incubated with survivin, surface binding and intracellular uptake of survivin by these T-cells occurred. ${ }^{63}$ Upon further investigation, a survivin-associated decreased proliferation was observed in these T-cells. In addition, analysis of cytotoxic T-lymphocytes revealed a reduction in their functional cytotoxicity. However, T-regulatory cell function remained unaltered. Importantly, the numbers of Th1 and Tc1 cells were significantly reduced, together with the cytokines associated with them (interferon- $\gamma$ and interleukin [IL]-2), while an increase in IL-4 $4^{+}$, IL- $5^{+}$, and IL- $13^{+}$T-cells was observed. These results suggest a skewing from a type 1 response, which mediates immunity with cytokines that enhance cellular cytolytic activity and can elicit an effective antitumor response to a type 2 T-cell response, which does not lead to tumor rejection and is frequently observed in cancer patients. ${ }^{59-62}$ The verification and molecular mechanism underlying this Th-cell plasticity is yet to be fully elucidated.

\section{Cancer-specific upregulation of survivin: breast cancer}

Breast cancer is the second most common cancer type (following lung cancer) and the most common cancer among women worldwide. ${ }^{1}$ It is estimated that in the US alone there are nearly 3 million women with diagnosed breast cancer and approximately 227,000 more will be added to that number this year. ${ }^{1}$ African American women are more likely than all other women to die from breast cancer, as their tumors often are discovered at a later, more advanced stage, leaving them fewer treatment options. ${ }^{63,64}$ There are several pathways involved in breast cancer pathogenesis with pathways of tumor cell death playing an important role in its development and maintenance. Among the proteins involved in cell death/survival pathways, survivin is one of the most studied. Using serial analysis of gene expression, survivin 
was found to be the fourth highest expressed transcript in a number of common cancers including breast cancers. ${ }^{65}$ In a study examining the interaction of the insulin-like growth factor (IGF)-II and survivin, Kalla Singh et $\mathrm{al}^{66}$ found that high IGF-II expression-regulation of survivin correlated and was significantly higher in African Americans than in Caucasians. In this study, it was shown that IFG-II regulates survivin, leading to the inhibition of mitochondrial membrane depolarization, cell survival, and chemoresistance. Furthermore, the effect of IGF-II and IGF-II siRNA on the expression of Bcl-2, Bcl-XL, and survivin in African American and Caucasian breast cancer cells was measured. IGF-II expression was shown to be causative in the upregulation of these antiapoptotic proteins, while IGF-II siRNA was prohibitive. ${ }^{66}$ This intriguing observation will require further investigation.

The different subcellular pools of survivin in breast cancer appear to have distinct functions. Adamkov et $\mathrm{al}^{67}$ suggested that nuclear staining of the survivin antigen could be used as a marker of the degree of neoplasia, while Rexhepaj et $a l^{68}$ suggested that increased levels of nuclear survivin are associated with a proliferative phenotype. One thing that is clear is that survivin plays a key role in the initiation and progression of breast cancer. High messenger (m)RNA expression was found to be an independent prognostic marker in breast cancer patients ${ }^{69}$ and survivin upregulation significantly correlated to lymph node involvement, tumor stage, and histological type. ${ }^{70}$ By contrast, others have shown that high levels of its expression are associated with a beneficial response to chemotherapy. ${ }^{71}$ This could be due to alternative splicing of survivin. Multiple studies demonstrate that alternative splicing patterns are altered during cancer progression. ${ }^{72}$ Several different mechanisms contribute to changes in the regulation of alternative splicing including stress, stimulation of receptors by growth factors, cytokines, hormones, etc. Survivin, to date, has six different described variants with different apoptotic properties and intracellular localization (Figure 2). ${ }^{73}$ Protein and mRNA levels of the pro- and antiapoptotic isoforms of survivin correlate with cancer prognosis. ${ }^{74}$

Early diagnosis of breast cancer is challenging due to a lack of serum biomarkers and, inadequate as it is, performed through invasive means such as needle biopsy, scanning, and invasive pathological examination. Despite the availability of numerous diagnostic and prognostic methods, there remains a need for an easy, sensitive, and noninvasive way to track tumor activity. We propose that through analysis of tumor exosomes and by specifically assaying these exosomes for tumor-specific antigens such as survivin, XIAP, cIAP1/2, and chaperone proteins such as HSP70 and HSP90, just such a biomarker discovery may 1 day be realized. We have found an extracellular survivin pool in serum exosomes in prostate ${ }^{52}$ and breast cancers. ${ }^{75}$ In these breast cancer patients' sera, we found

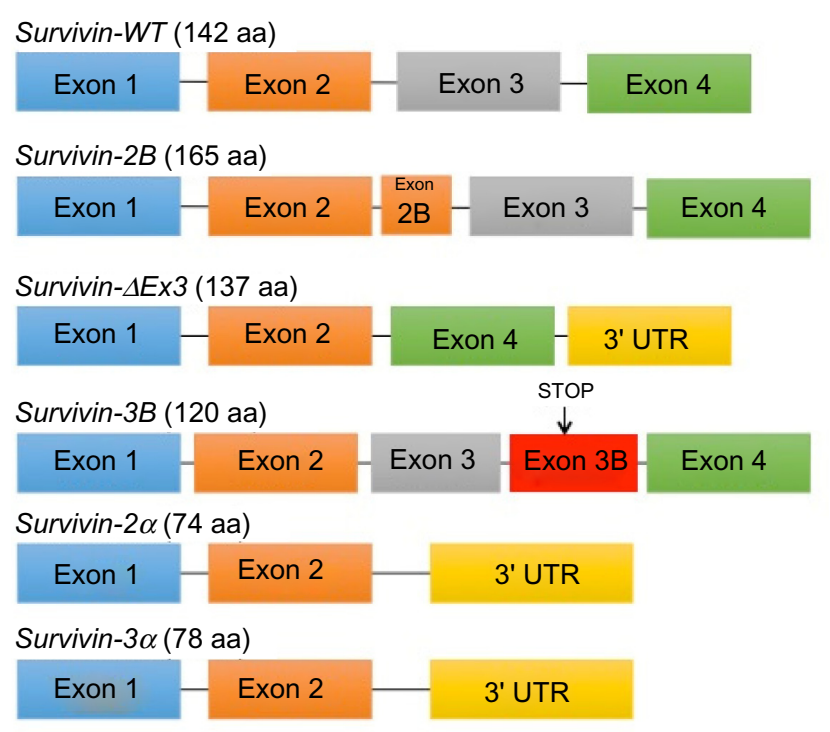

\section{Generalized outcome of overexpression}

Antiapoptotic
adverse
$\begin{gathered}\text { Conflicting (adverse in } \\ \text { some studies/beneficial } \\ \text { in others) }\end{gathered}$
Antiapoptotic
adverse
Antiapoptotic
adverse
Antiapoptotic
adverse

Figure 2 Splicing of the human survivin premessenger RNA produces six different splice variants.

Notes: With the exception of survivin- $3 \alpha$ and survivin- $2 B$, survivin-WT, survivin- $\Delta$ Ex 3 , survivin- $3 B$, and survivin- $2 \alpha$ are all associated with unfavorable antiapoptotic phenotypes. Survivin- $2 B$ has been shown to have either a favorable or unfavorable association, depending upon the cancer type it is expressed in, and survivin-3 $\alpha$ has yet to be determined. Abbreviations: WT, wild type; UTR, untranslated region. 
survivin levels and exosome numbers to be significantly increased over controls with a disparate expression of the survivin splice variants similar to that observed in tissues. It is important though that we recognize the possible confounding factors such as comorbidities, psychological complications, genetics, and environmental exposures that could affect these results.

\section{Cancer-specific upregulation of survivin: prostate cancer}

$\mathrm{PCa}$ is the most frequently diagnosed nonskin cancer in men and the second leading cause of male cancer deaths in the US, accounting for 238,590 new cases and 29,720 deaths in 2013., ${ }^{1,76}$ These statistics have undergone minimal changes despite advances in screening and early diagnosis, and therefore still require a significant investment if $\mathrm{PCa}$ is to be defeated. As has recently been described by our colleagues, African American men have a growing disparity in their $\mathrm{PCa}$ incidence and mortality compared to other ethnic groups, ${ }^{77}$ and they present with the disease at a much younger age than do Caucasian men, which is a trait common in more aggressive cancers. ${ }^{78,79}$

Survivin is expressed in PCa and has been shown to be upregulated in order to protect the PCa microenvironment against apoptosis and oxidative stress-induced damage. ${ }^{80}$ Survivin, therefore, directly and/or indirectly influences cell survival and death. Shariat et al, using immunohistochemistry, compared survivin protein expression in normal and malignant prostate tissue and lymph node tissue from $\mathrm{PCa}$ patients. There appeared to be a gradual but consistent rise of survivin expression from normal prostate specimens (36\%) to PCa (71\%), with the highest expression found in metastatic lymph nodes $(81 \%) .{ }^{81}$ Survivin expression therefore seemed to correlate with the degree of transition from normal prostate epithelia to a more aggressive form of $\mathrm{PCa}$ (metastatic PCa).

Our group recently looked at relative levels of survivin in the sera of PCa patients and compared it to that of patients with BPH and from subjects with no diagnosis of cancer or $\mathrm{BPH} .{ }^{52}$ Survivin levels proved to exhibit a stronger correlation in our hands than prostate-specific antigen when it came to distinguishing the two clinical conditions. We therefore propose that exosomal survivin evaluation should be given serious consideration as a plausible biomarker for the early detection of $\mathrm{PCa}$ and perhaps could be used to monitor treatment efficacy and disease recurrence. Higher levels of not only survivin but its splice variants $2 \mathrm{~B}$ and $2 \alpha$, both in vitro and in tissue, seem to correlate with PCa cell proliferation and a more aggressive phenotype. ${ }^{82}$ The intracellular compartment localization of survivin has been suggested to be of prognostic value. When tissues of patients with locally advanced PCa were stained and examined for survivin, patients with higher levels of intranuclear survivin exhibited improved survival, whereas those with higher levels of cytoplasmic survivin exhibited a poorer prognosis. ${ }^{83}$

In summary, survivin, in $\mathrm{PCa}$ has a dual role as an inhibitor of apoptosis and cell cycle mediator. Its level of expression appears to correlate with the progression from normal to indolent and to a more aggressive form of PCa. Our demonstration of exosomal survivin in the plasma of patients with newly diagnosed low-grade $\mathrm{PCa}^{52}$ provides a rationale for studies to investigate the utility of exosomal survivin as an early, easily measured biomarker for $\mathrm{PCa}$ diagnosis, as well as a marker to monitor treatment efficacy and tumor recurrence.

\section{Cancer-specific upregulation of survivin: pancreatic cancer}

Cancer of the pancreas is the fourth most common cause of cancer death in men and women in the US. In 2013, an estimated 45,220 new cases and 38,460 deaths from pancreatic cancer occurred. ${ }^{1}$ It is a highly malignant disease and lacks clear early warning signs or symptoms thus remaining silent in its victims until it is well advanced. The vast majority of patients are not diagnosed until stage III or IV, and once diagnosed, exhibit a median survival of 4-8 months with a 5 -year survival rate being $<5 \% .{ }^{84}$ Risk factors include sex, age, diabetes, chronic pancreatitis, family history, smoking, alcohol abuse, and possibly diets high in fat ${ }^{84}$ Early diagnosis continues to be the greatest obstacle and there is an urgent need for screening biomarkers.

Pancreatic cancer incidence in the US is higher in African Americans and Hispanics than in Caucasians. ${ }^{85,86}$ In a number of recent studies, the risk factors in men (cigarette smoking and diabetes mellitus) and women (moderate/heavy alcohol consumption and an elevated body mass index [obesity]), explain almost the entire African American/non-Hispanic White disparity in incidence. ${ }^{85,86} \mathrm{In}$ the absence of these risk factors, pancreatic adenocarcinoma incidence rates among African Americans do not exceed those of Caucasians from either men or women. ${ }^{87-89}$ In 2003, a group at the Barbara Ann Karmanos Cancer Institute analyzed a group of pancreatic cancer patients (166 African American, 244 Caucasian) for clinicopathologic characteristics of the disease, as well as for immunohistochemical expression of commonly found pancreatic cancer biomarkers: Fas, FasL, p21/waf-1, p27, 
p53, and Her2. They also investigated the presence and types of K-ras mutations at codon $12 .{ }^{90}$ African Americans were found to have significantly higher rates of K-ras mutations than did Caucasians, and their treatment with chemotherapy or radiation therapy was also much less effective than that recorded in Caucasians. African Americans more frequently than Caucasians were found with positive surgical margins and many clinicopathologic variables such as median survival, 5-year survival, and stage at presentation were different. African Americans were less immunoreactive to Fas expression and had a much stronger Her2 expression than did Caucasians. ${ }^{90}$

As in prostate and breast cancer, as previously discussed, epidemiological evidence exists for a strong association between pancreatic cancer and a high consumption of dietary fat. Dietary fat is made up of fatty acids and lipids that are metabolized into arachidonic acid. The key enzymes for arachidonic acid metabolism are lipoxygenases (LOXs) and cyclooxygenases (COXs) which, outside of dietary fat research, have been shown to be associated with the development and progression of pancreatic cancer. ${ }^{11} \mathrm{LOX}$ and COX inhibitors prohibit the continued progression of pancreatic cancer and induce intrinsic mitochondria-associated apoptotic cell death..$^{92}$

There have been numerous studies performed on the prognostic implications of survivin in pancreatic cancer. A high expression of survivin was found to be related to shorter survival in patients with resected pancreatic adenocarcinoma. ${ }^{93}$ In contrast, high nuclear levels of survivin predicted better prognosis than cytoplasmic survivin. ${ }^{94}$ Furthermore, Sagol et $\mathrm{a}^{95}$ and Sun et $\mathrm{a}^{96}$ showed no significant association between survivin and long-term survival. Targeting survivin early on in the process could play an invaluable role in preventing the progression to malignancy. In addition, a screening biomarker that could potentially detect early stages of the disease is of utmost importance.

\section{Cancer-specific upregulation of survivin: hematological malignancies}

Hematological malignancies such as leukemia, lymphoma, myeloma, and myelodysplastic syndromes affect the bone marrow, the blood cells, the lymph nodes, and other parts of the lymphatic system. These pathologies are interrelated, likely the result of acquired changes to the DNA of a single stem cell. Approximately 140,000 people will be diagnosed with leukemia, lymphoma, or myeloma, accounting for approximately $9 \%$ of all new cancers diagnosed each year in the US. ${ }^{97}$ Of particular interest is multiple myeloma, which accounts for $\sim 10 \%$ of all hematologic malignancies diagnosed in the US annually ${ }^{98}$ Among the hematological malignancies, multiple myeloma is known to affect individuals from ethnically diverse populations in a disparate manner.

In accordance with reports for many types of solid tumors, ${ }^{27,99}$ cancer-specific upregulation of survivin also occurs in hematological malignancies, ${ }^{100,101}$ though to date, there have been no published reports taking ethnicity into account. In hematological cancers, expression of survivin is associated with poor clinical outcomes and resistance to chemotherapy. ${ }^{102-105}$ Survivin expression levels are linked to risk of early relapse in pediatric B-cell acute lymphoblastic leukemia, ${ }^{106-108}$ and to tumor aggressiveness ${ }^{109}$ and chemoresistance in adult acute lymphoblastic leukemia. ${ }^{110}$

High levels of survivin expression have also been linked to cell proliferation and antiapoptotic characteristics in chronic myelogenous leukemia ${ }^{111}$ and chronic lymphocytic leukemia. ${ }^{112}$ In acute myeloid leukemia, levels of survivin expression were found to be significantly predictive of shorter overall and event-free survival. ${ }^{113}$ In addition, the highest survivin expression levels are detected in the CD34(+)CD38(-) acute myeloid leukemia stem/progenitor cell populations, ${ }^{113}$ further validating survivin's potential as a prognostic biomarker and therapeutic target. Overexpression of survivin in CD34+ hematopoietic cells has been found to induce hematological malignancies in vivo, suggesting that it has a role in the development of these diseases. ${ }^{114}$

Localization of survivin to the nucleus versus the cytoplasm is very important because the functional dynamics of survivin are dependent on the site of survivin expression. ${ }^{115}$ Using chemotherapeutic drugs in hematologic cancer, Bernardo et $\mathrm{al}^{116}$ reported that cytoplasmic survivin was more relevant to the apoptotic index than that associated with nuclear survivin. Investigating survivin's cellular locations, alternative splice variant profiles within the context of cancer health disparities and novel therapeutic modalities will continue to be important areas of study.

\section{Liquid biopsy}

The tumor microenvironment is being increasingly recognized as providing many key factors necessary for many of the stages of disease progression including local resistance, immune escape, and distant metastasis. Understanding this tumor microenvironment, including the cells involved and the communications ongoing between them, will continue to prove instrumental in our understanding of cancer and eventually our ability to control it, if not terminate it. In order to fully "learn the language", there is a need for new 
biomarker discovery. Specifically, biomarkers that are easily isolated and identified from blood, urine, saliva, cerebral spinal fluid, ascites, etc, as well as from tissue biopsies, will need to be identified. The term "liquid biopsy" has been used recently to describe the source of these biomarkers and could be defined as broadly as circulating tumor cells, circulating tumor DNA, exosomes, and secretomes. ${ }^{48}$ Differential expression of exosomal survivin may serve as a diagnostic and or prognostic marker in early cancer patients, and it may soon lead to the development of potential therapeutics for the treatment of these diseases.

\section{Conclusion}

Most efforts on the identification of candidate cancer biomarkers, and on analyzing differences in the cancer biology that exists between African Americans and Caucasian patients, have focused on gene expression differentials in tumor tissues, epigenetic issues (such as methylation patterns), and on single nucleotide polymorphisms (SNPs). While these efforts have been necessary in providing important clues for understanding the biochemical mechanisms associated with cancer health disparities, it is also imperative to develop noninvasive approaches that analyze, indirectly and early in the disease process, the molecular profiles of tumors. One recent study has investigated the $-31 \mathrm{G}>\mathrm{C}$ survivin promoter polymorphism across approximately 7,500 cancer cases and 9,000 controls. ${ }^{117}$ This polymorphism was significantly associated with an increased cancer risk in colorectal, gastric, and urothelial cancers. In contrast, this SNP was remarkably decreased in patients with hepatocellular carcinoma. With regard to ethnic diversity, this SNP was shown to increase cancer risk in Asian populations, ${ }^{117}$ as well as a higher Wilms' tumor risk in Serbian children. ${ }^{118}$ Findings such as these encourage us to not only look at the overall abundance of gene or protein products in racial disparities and cancer but also look deeper into the minutia that may have been historically overlooked and may provide important insights not before recognized as factors in cancer development and resistance.

Recent studies have shown that small membrane-bound vesicles called exosomes constitute the latest mode of intercellular information transfer or communication. This exchange of molecular information is facilitated by their unique composition, which is enriched with enzymes, structural proteins, adhesion molecules, lipid rafts, microRNA, and RNA. Importantly, cancer cells have been shown to secrete more exosomes than do their normal counterparts, indicating that exosomes can be used as diagnostic markers and their active secretion has functional implications. In addition, recent studies revealed that genes involved in inflammation and autoimmune responses are differentially upregulated in cancer patients compared to controls. This could imply that differences in antitumor immune responses may exist between racial groups in tumors.

It is very important to specifically target survivin in a defined location for therapeutic purposes. Survivin is a unique inhibitor of apoptosis with triple functionality: in cell cycle regulation when it is present in the nucleus; inhibition of apoptosis when it is in the mitochondria; and resistance to chemotherapy when it exists in the tumor microenvironment packaged in exosomes. Survivin's upregulation in specific cancers, in addition to its presence in serum exosomes, makes it an important molecule as a diagnostic as well as prognostic marker. Unfortunately, controversy exists as to whether survivin expression is favorable or unfavorable in the outcome of cancer. Survivin expression is an unfavorable prognostic indicator in esophageal, hepatocellular, and ovarian cancers, cholangiocarcinoma, and endometrial cancers, but it has associated favorable outcomes in gastric, bladder, breast, ependymoma osteosarcoma, and pancreatic ductal adenocarcinomas. ${ }^{113,119}$ To validate its role, a large number of case-control studies need to be adapted. Subsequent studies exploiting the exosomal packaging of survivin may also 1 day be used in cancer therapeutics.

In conclusion, this review addresses an urgent need in the fight against cancer health disparities: the need to identify and evaluate novel serum biomarkers such as survivin and its alternative splice variants for the noninvasive, early detection of cancer in interventions that can be tailored to Americans of different ethnicities, ultimately paving the way for future studies focused on analyzing these biomarkers in larger cohorts of ethnically diverse cancer patients.

\section{Informed consent and animal studies}

No animal or human studies were carried out by the authors for this article.

\section{Acknowledgments}

Funding for our laboratory comes from grants for health disparity research: NIH-NCMHD Project EXPORT Program 5P20MD001631/Project 3 (NRW); and NIH-NIMHD P20-MD006988 subproject 2. Funding also comes from a National Merit Test Bed (NMTB) award sponsored by the Department of the Army under Cooperative Agreement Number DAMD17-97-2-7016 (NRW). The funders had no 
role in the study design, data collection and analysis, the decision to publish, or preparation of the manuscript. We would like to thank the entire NRW lab for careful review of the manuscript.

\section{Disclosure}

The authors report no conflicts of interest in this work.

\section{References}

1. Siegel R, Naishadham D, Jemal A. Cancer statistics, 2013. CA Cancer J Clin. 2013;63(1):11-30.

2. Sharp L, Deady S, Gallagher P, et al. The magnitude and characteristics of the population of cancer survivors: using population-based estimates of cancer prevalence to inform service planning for survivorship care. BMC Cancer. 2014;14:767.

3. Jadav S, Rajan SS, Abughosh S, Sansgiry SS. The role of socioeconomic status and health care access in breast cancer screening compliance among Hispanics. J Public Health Manag Pract. Epub March 9, 2015.

4. Beydoun HA, Beydoun MA. Predictors of colorectal cancer screening behaviors among average-risk older adults in the United States. Cancer Causes Control. 2008;19(4):339-359.

5. Guessous I, Dash C, Lapin P, Doroshenk M, Smith RA, Klabunde CN; National Colorectal Cancer Roundtable Screening Among the 65 Plus Task Group. Colorectal cancer screening barriers and facilitators in older persons. Prev Med. 2010;50(1-2):3-10.

6. Tsai CJ, Giovannucci EL. Hyperinsulinemia, insulin resistance, vitamin D, and colorectal cancer among whites and African Americans. Dig Dis Sci. 2012;57(10):2497-2503.

7. Palmer S. Diet, nutrition and cancer. Prog Food Nutr Sci. 1985; 9(34):283-341.

8. Takachi R, Tsubono Y, Baba K, et al. Red meat intake may increase the risk of colon cancer in Japanese, a population with relatively low red meat consumption. Asia Pac J Clin Nutr. 2011;20(4):603-612.

9. Kono S. [Host and environmental factors predisposing to cancer development]. Gan To Kagaku Ryoho. 2010;37(4):571-576. Japanese.

10. Kasuga M, Ueki K, Tajima N, et al. Report of the Japan Diabetes Society/ Japanese Cancer Association Joint Committee on Diabetes and Cancer. Cancer Sci. 2013;104(7):965-976.

11. Guthrie N, Carroll KK. Specific versus non-specific effects of dietary fat on carcinogenesis. Prog Lipid Res. 1999;38(3):261-271.

12. Nakamura K, Nagata C, Wada K, et al. Cigarette smoking and other lifestyle factors in relation to the risk of pancreatic cancer death: a prospective cohort study in Japan. Jpn J Clin Oncol. 2011;41(2):225-231.

13. De Pergola G, Silvestris F. Obesity as a major risk factor for cancer. J Obes. 2013;2013:291546.

14. Reed JC. The Survivin saga goes in vivo. J Clin Invest. 2001;108(7): 965-969.

15. Li F, Ambrosini G, Chu EY, et al. Control of apoptosis and mitotic spindle checkpoint by survivin. Nature. 1998;396(6711):580-584.

16. Andersen MH, Svane IM, Becker JC, Straten PT. The universal character of the tumor-associated antigen survivin. Clin Cancer Res. 2007;13(20):5991-5994.

17. Altieri DC. Survivin, versatile modulation of cell division and apoptosis in cancer. Oncogene. 2003;22(53):8581-8589.

18. Altieri DC. The case for survivin as a regulator of microtubule dynamics and cell death decisions. Curr Opin Cell Biol. 2006;18(6): 609-615.

19. Dohi T, Beltrami E, Wall NR, Plescia J, Altieri DC. Mitochondrial survivin inhibits apoptosis and promotes tumorigenesis. $J$ Clin Invest. 2004;114(8):1117-1127.

20. Fortugno P, Wall NR, Giodini A, et al. Survivin exists in immunochemically distinct subcellular pools and is involved in spindle microtubule function. J Cell Sci. 2002;115(Pt 3):575-585.
21. Khan S, Aspe JR, Asumen MG, et al. Extracellular, cell-permeable survivin inhibits apoptosis while promoting proliferative and metastatic potential. Br J Cancer. 2009;100(7):1073-1086.

22. Khan S, Jutzy JM, Aspe JR, McGregor DW, Neidigh JW, Wall NR. Survivin is released from cancer cells via exosomes. Apoptosis. 2011; 16(1):1-12.

23. Webber J, Yeung V, Clayton A. Extracellular vesicles as modulators of the cancer microenvironment. Semin Cell Dev Biol. 2015; 40:27-34.

24. Li F, Ackermann EJ, Bennett CF, et al. Pleiotropic cell-division defects and apoptosis induced by interference with survivin function. Nat Cell Biol. 1999;1(8):461-466.

25. Li F, Ling X. Survivin study: an update of "what is the next wave"? J Cell Physiol. 2006;208(3):476-486.

26. Yang D, Welm A, Bishop JM. Cell division and cell survival in the absence of survivin. Proc Natl Acad Sci U S A. 2004;101(42): 15100-15105.

27. Church DN, Talbot DC. Survivin in solid tumors: rationale for development of inhibitors. Curr Oncol Rep. 2012;14(2):120-128.

28. Altieri DC. Survivin, cancer networks and pathway-directed drug discovery. Nat Rev Cancer. 2008;8(1):61-70.

29. Dong Z, Venkatachalam MA, Wang J, et al. Up-regulation of apoptosis inhibitory protein IAP-2 by hypoxia. Hif-1-independent mechanisms. J Biol Chem. 2001;276(22):18702-18709.

30. Dohi T, Okada K, Xia F, et al. An IAP-IAP complex inhibits apoptosis. J Biol Chem. 2004;279(33):34087-34090.

31. Zagórska A, Dulak J. HIF-1: the knowns and unknowns of hypoxia sensing. Acta Biochim Pol. 2004;51(3):563-585.

32. Tamm I, Wang Y, Sausville E, et al. IAP-family protein survivin inhibits caspase activity and apoptosis induced by Fas (CD95), Bax, caspases, and anticancer drugs. Cancer Res. 1998;58(23):5315-5320.

33. Banks DP, Plescia J, Altieri DC, et al. Survivin does not inhibit caspase-3 activity. Blood. 2000;96(12):4002-4003.

34. Marusawa $\mathrm{H}$, Matsuzawa $\mathrm{S}$, Welsh $\mathrm{K}$, et al. HBXIP functions as a cofactor of survivin in apoptosis suppression. EMBO J. 2003;22(11): 2729-2740.

35. Denzer K, Kleijmeer MJ, Heijnen HF, Stoorvogel W, Geuze HJ. Exosome: from internal vesicle of the multivesicular body to intercellular signaling device. J Cell Sci. 2000;113 Pt 19:3365-3374.

36. Keller S, Sanderson MP, Stoeck A, Altevogt P. Exosomes: from biogenesis and secretion to biological function. Immunol Lett. 2006;107(2):102-108.

37. Simpson RJ, Lim JW, Moritz RL, Mathivanan S. Exosomes: proteomic insights and diagnostic potential. Expert Rev Proteomics. 2009; 6(3):267-283.

38. Greening DW, Gopal SK, Xu R, Simpson RJ, Chen W. Exosomes and their roles in immune regulation and cancer. Semin Cell Dev Biol. 2015;40:72-81.

39. Wolfers J, Lozier A, Raposo G, et al. Tumor-derived exosomes are a source of shared tumor rejection antigens for CTL cross-priming. Nat Med. 2001;7(3):297-303.

40. Andre F, Schartz NE, Movassagh M, et al. Malignant effusions and immunogenic tumour-derived exosomes. Lancet. 2002;360(9329):295-305.

41. Wieckowski E, Whiteside TL. Human tumor-derived vs dendritic cellderived exosomes have distinct biologic roles and molecular profiles. Immunol Res. 2006;36(1-3):247-254.

42. Zitvogel L, Regnault A, Lozier A, et al. Eradication of established murine tumors using a novel cell-free vaccine: dendritic cell-derived exosomes. Nat Med. 1998;4(5):594-600.

43. Alečković M, Kang Y. Regulation of cancer metastasis by cell-free miRNAs. Biochim Biophys Acta. 2015;1855(1):24-42.

44. Altieri DC. Validating survivin as a cancer therapeutic target. Nat Rev Cancer. 2003;3(1):46-54.

45. Ginestra A, La Placa MD, Saladino F, Cassarà D, Nagase H, Vittorelli ML. The amount and proteolytic content of vesicles shed by human cancer cell lines correlates with their in vitro invasiveness. Anticancer Res. 1998;18(5A):3433-3437. 
46. Ginestra A, Miceli D, Dolo V, Romano FM, Vittorelli ML. Membrane vesicles in ovarian cancer fluids: a new potential marker. Anticancer Res. 1999;19(4C):3439-3445.

47. Nilsson J, Skog J, Nordstrand A, et al. Prostate cancer-derived urine exosomes: a novel approach to biomarkers for prostate cancer. $\mathrm{Br} \mathrm{J}$ Cancer. 2009;100(10):1603-1607.

48. Rolfo C, Castiglia M, Hong D, et al. Liquid biopsies in lung cancer: the new ambrosia of researchers. Biochim Biophys Acta. 2014; 1846(2):539-546.

49. Adams M, Navabi H, Croston D, et al. The rationale for combined chemo/immunotherapy using a Toll-like receptor 3 (TLR3) agonist and tumour-derived exosomes in advanced ovarian cancer. Vaccine. 2005;23(17-18):2374-2378.

50. Shender VO, Pavlyukov MS, Ziganshin RH, et al. Proteome-metabolome profiling of ovarian cancer ascites reveals novel components involved in intercellular communication. Mol Cell Proteomics. 2014; 13(12):3558-3571.

51. Park JO, Choi DY, Choi DS, et al. Identification and characterization of proteins isolated from microvesicles derived from human lung cancer pleural effusions. Proteomics. 2013;13(14):2125-2134.

52. Khan S, Jutzy JM, Valenzuela MM, et al. Plasma-derived exosomal survivin, a plausible biomarker for early detection of prostate cancer. PLoS One. 2012;7(10):e46737.

53. Zangemeister-Wittke U, Simon HU. An IAP in action: the multiple roles of survivin in differentiation, immunity and malignancy. Cell Cycle. 2004;3(9):1121-1123.

54. Xing Z, Conway EM, Kang C, Winoto A. Essential role of survivin, an inhibitor of apoptosis protein, in T cell development, maturation, and homeostasis. J Exp Med. 2004;199(1):69-80.

55. Mera S, Magnusson M, Tarkowski A, Bokarewa M. Extracellular survivin up-regulates adhesion molecules on the surface of leukocytes changing their reactivity pattern. $J$ Leukoc Biol. 2008;83(1): 149-155.

56. Tanaka M, Butler MO, Ansén S, et al. Induction of HLA-DP4-restricted anti-survivin Th1 and Th2 responses using an artificial antigenpresenting cell. Clin Cancer Res. 2011;17(16):5392-5401.

57. Yang $Z$, Wang $L$, Wang $H$, et al. A novel mimovirus vaccine containing survivin epitope with adjuvant IL-15 induces long-lasting cellular immunity and high antitumor efficiency. Mol Immunol. 2008;45(6):1674-1681.

58. Lladser A, Párraga M, Quevedo L, et al. Naked DNA immunization as an approach to target the generic tumor antigen survivin induces humoral and cellular immune responses in mice. Immunobiology. 2006;211(1-2):11-27.

59. Wan YY. Multi-tasking of helper T cells. Immunology. 2010;130(2): 166-171.

60. Pietra G, Manzini C, Rivara S, et al. Melanoma cells inhibit natural killer cell function by modulating the expression of activating receptors and cytolytic activity. Cancer Res. 2012;72(6):1407-1415.

61. Amarnath S, Maqus CW, Wang JC, et al. The PDL1-PD1 axis converts human TH1 cells into regulatory T cells. Sci Transl Med. 2011;3(111):111ra120.

62. Jutzy JM, Khan S, Asuncion-Valenzuela MM, Milford TA, Payne KJ, Wall NR. Tumor-released survivin induces a type- $2 \mathrm{t}$ cell response and decreases cytotoxic $\mathrm{T}$ cell function, in vitro. Cancer Microenviron. 2013;6(1):57-68.

63. Dehal A, Abbas A, Johna S. Racial disparities in clinical presentation, surgical treatment and in-hospital outcomes of women with breast cancer: analysis of nationwide inpatient sample database. Breast Cancer Res Treat. 2013;139(2):561-569.

64. Johnson RH, Chien FL, Bleyer A. Incidence of breast cancer with distant involvement among women in the United States, 1976 to 2009. JAMA. 2013;309(8):800-805.

65. Velculescu VE, Madden SL, Zhang L, et al. Analysis of human transcriptomes. Nat Genet. 1999;23(4):387-388.

66. Kalla Singh S, Tan QW, Brito C, De León M, Garberoglio C, De León D. Differential insulin-like growth factor II (IGF-II) expression: A potential role for breast cancer survival disparity. Growth Horm IGF Res. 2010;20(2):162-170.
67. Adamkov M, Kajo K, Vybohova D, Krajcovic J, Stuller F, Rajcani J. Correlations of survivin expression with clinicomorphological parameters and hormonal receptor status in breast ductal carcinoma. Neoplasma. 2012;59(1):30-37.

68. Rexhepaj E, Jirstrom K, O'Connor DP, et al. Validation of cytoplasmicto-nuclear ratio of survivin as an indicator of improved prognosis in breast cancer. BMC Cancer. 2010;10:639.

69. Xu C, Yamamoto-Ibusuki M, Yamamoto Y, et al. High survivin mRNA expression is a predictor of poor prognosis in breast cancer: a comparative study at the mRNA and protein level. Breast Cancer. 2014;21(4):482-490.

70. Dedić Plavetić N, Jakić-Razumović J, Kulić A, Vrbanec D. Prognostic value of proliferation markers expression in breast cancer. Med Oncol. 2013;30(2):523.

71. Span PN, Tjan-Heijnen VC, Manders P, van Tienoven D, Lehr J, Sweep FC. High survivin predicts a poor response to endocrine therapy, but a good response to chemotherapy in advanced breast cancer. Breast Cancer Res Treat. 2006;98(2):223-230.

72. Li F. Role of survivin and its splice variants in tumorigenesis. $\mathrm{Br} J$ Cancer. 2005;92(2):212-216.

73. Necochea-Campion Rd, Chen CS, Mirshahidi S, Howard FD, Wall NR. Clinico-pathologic relevance of Survivin splice variant expression in cancer. Cancer Lett. 2013;339(2):167-174.

74. Boidot R, Vegran F, Lizard-Nacol S. Predictive value of survivin alternative transcript expression in locally advanced breast cancer patients treated with neoadjuvant chemotherapy. Int $J$ Mol Med. 2009;23(2):285-291.

75. Khan S, Bennit HF, Turay D, et al. Early diagnostic value of survivin and its alternative splice variants in breast cancer. BMC Cancer. 2014; 14:176.

76. Brawley OW. Prostate cancer epidemiology in the United States. World J Urol. 2012;30(2):195-200.

77. Basu A, Banerjee H, Rojas H, et al. Differential expression of peroxiredoxins in prostate cancer: consistent upregulation of PRDX3 and PRDX4. Prostate. 2011;71(7):755-765.

78. Hoffman RM, Gilliland FD, Eley JW, et al. Racial and ethnic differences in advanced-stage prostate cancer: the Prostate Cancer Outcomes Study. J Natl Cancer Inst. 2001;93(5):388-395.

79. Karami S, Young HA, Henson DE. Earlier age at diagnosis: another dimension in cancer disparity? Cancer Detect Prev. 2007; 31(1):29-34.

80. Zaffaroni N, Pennati M, Daidone MG. Survivin as a target for new anticancer interventions. J Cell Mol Med. 2005;9(2):360-372.

81. Shariat SF, Lotan Y, Saboorian H, et al. Survivin expression is associated with features of biologically aggressive prostate carcinoma. Cancer. 2004;100(4):751-757.

82. Koike H, Sekine Y, Kamiya M, Nakazato H, Suzuki K. Gene expression of survivin and its spliced isoforms associated with proliferation and aggressive phenotypes of prostate cancer. Urology. 2008; 72(6):1229-1233.

83. Zhang M, Ho A, Hammond EH, et al. Prognostic value of survivin in locally advanced prostate cancer: study based on RTOG 8610 . Int $J$ Radiat Oncol Biol Phys. 2009;73(4):1033-1042.

84. Lowenfels AB, Maisonneuve P. Epidemiology and risk factors for pancreatic cancer. Best Pract Res Clin Gastroenterol. 2006;20(2): 197-209.

85. Gordis L, Gold EB. Epidemiology and Etiology of Pancreatic Cancer. In: Go et al, editors. Pancreas, Biology, and Pathobiology of Disease Second Edition. New York:Raven Press;1993:837-855.

86. Woutersen RA, Appel MJ, van Garderen-Hoetmer A, Wijnands MV. Dietary fat and carcinogenesis. Mutat Res. 1999;443(1-2):111-127.

87. Singal V, Singal AK, Kuo YF. Racial disparities in treatment for pancreatic cancer and impact on survival: a population-based analysis. J Cancer Res Clin Oncol. 2012;138(4):715-722.

88. Hayanga AJ. Risk of pancreatic adenocarcinoma: disparity between African Americans and other race/ethnic groups. Cancer. 2005;104(11):2530-2531; author reply 2531. 
89. Chang KJ, Parasher G, Christie C, Largent J, Anton-Culver H. Risk of pancreatic adenocarcinoma: disparity between African Americans and other race/ethnic groups. Cancer. 2005;103(2):349-357.

90. Pernick NL, Sarkar FH, Philip PA, et al. Clinicopathologic analysis of pancreatic adenocarcinoma in African Americans and Caucasians. Pancreas. 2003;26(1):28-32.

91. Ding XZ, Tong WG, Adrian TE. Cyclooxygenases and lipoxygenases as potential targets for treatment of pancreatic cancer. Pancreatology. 2001;1(4):291-299

92. Tong WG, Ding XZ, Witt RC, Adrian TE. Lipoxygenase inhibitors attenuate growth of human pancreatic cancer xenografts and induce apoptosis through the mitochondrial pathway. Mol Cancer Ther. 2002;1(11):929-935.

93. Xie H, Jiang W, Xiao SY, Liu X. High expression of survivin is prognostic of shorter survival but not predictive of adjuvant gemcitabine benefit in patients with resected pancreatic adenocarcinoma. J Histochem Cytochem. 2013;61(2):148-155.

94. Tonini G, Vincenzi B, Santini D, et al. Nuclear and cytoplasmic expression of survivin in 67 surgically resected pancreatic cancer patients Br J Cancer. 2005;92(12):2225-2232.

95. Sagol O, Yavuzsen T, Oztop I, et al. The effect of apoptotic activity, survivin, Ki-67, and P-glycoprotein expression on prognosis in pancreatic carcinoma. Pancreas. 2005;30(4):343-348.

96. Sun HC, Qiu ZJ, Liu J, et al. Expression of hypoxia-inducible factor-1 alpha and associated proteins in pancreatic ductal adenocarcinoma and their impact on prognosis. Int J Oncol. 2007;30(6):1359-1367.

97. The Leukemia and Lymphoma Society [webpage on the Internet]. Facts and statistics. White Plains, NY: The Leukemia and Lymphoma Society; 2015. Available from: http:/www.lls.org/diseaseinformation/ getinformationsupport/factsstatistics/. Accessed February 15, 2015.

98. Pulte D, Redaniel MT, Brenner H, Jeffreys M. Changes in survival by ethnicity of patients with cancer between 1992-1996 and 2002-2006: is the discrepancy decreasing? Ann Oncol. 2012;23(9):2428-2434.

99. Waligórska-Stachura J, Jankowska A, Waśko R, et al. Survivin - prognostic tumor biomarker in human neoplasms - review. Ginekol Pol. 2012;83(7):537-540.

100. Fulda S. Inhibitor of apoptosis proteins in hematological malignancies. Leukemia. 2009;23(3):467-476.

101. Fulda S. Exploiting inhibitor of apoptosis proteins as therapeutic targets in hematological malignancies. Leukemia. 2012;26(6):1155-1165.

102. Kamihira S, Yamada Y, Hirakata Y, et al. Aberrant expression of caspase cascade regulatory genes in adult T-cell leukaemia: survivin is an important determinant for prognosis. $\mathrm{Br} J$ Haematol. 2001;114(1):63-69.

103. Adida C, Recher C, Raffoux E, et al. Expression and prognostic significance of survivin in de novo acute myeloid leukaemia. $\mathrm{Br} J$ Haematol. 2000;111(1):196-203.

104. Park E, Gang EJ, Hsieh YT, et al. Targeting survivin overcomes drug resistance in acute lymphoblastic leukemia. Blood. 2011; 118(8):2191-2199.

Biologics: Targets \& Therapy

\section{Publish your work in this journal}

Biologics: Targets \& Therapy is an international, peer-reviewed journal focusing on the patho-physiological rationale for and clinical application of Biologic agents in the management of autoimmune diseases, cancers or other pathologies where a molecular target can be identified This journal is indexed on PubMed Central, CAS, EMBase, Scopus
105. Kelly RJ, Lopez-Chavez A, Citrin D, Janik JE, Morris JC. Impacting tumor cell-fate by targeting the inhibitor of apoptosis protein survivin. Mol Cancer. 2011;10:35.

106. Troeger A, Siepermann M, Escherich G, et al. Survivin and its prognostic significance in pediatric acute B-cell precursor lymphoblastic leukemia. Haematologica. 2007;92(8):1043-1050.

107. Esh AM, Atfy M, Azizi NA, El Naggar MM, Khalil EE, Sherief L. Prognostic significance of survivin in pediatric acute lymphoblastic leukemia. Indian J Hematol Blood Transfus. 2011;27(1):18-25.

108. Tyner JW, Jemal AM, Thayer M, Druker BJ, Chang BH. Targeting survivin and p53 in pediatric acute lymphoblastic leukemia. Leukemia. 2012;26(4):623-632.

109. Ahmed MB, Shehata HH, Moussa M, Ibrahim TM. Prognostic significance of survivin and tumor necrosis factor-alpha in adult acute lymphoblastic leukemia. Clin Biochem. 2012;45(1-2):112-116.

110. Morrison DJ, Hogan LE, Condos G, et al. Endogenous knockdown of survivin improves chemotherapeutic response in ALL models. Leukemia. 2012;26(2):271-279.

111. Wang Z, Sampath J, Fukuda S, Pelus LM. Disruption of the inhibitor of apoptosis protein survivin sensitizes Bcr-abl-positive cells to STI571-induced apoptosis. Cancer Res. 2005;65(18):8224-8232.

112. Grzybowska-Izydorczyk O, Cebula B, Robak T, Smolewski P. Expression and prognostic significance of the inhibitor of apoptosis protein (IAP) family and its antagonists in chronic lymphocytic leukaemia. Eur J Cancer. 2010;46(4):800-810.

113. Carter BZ, Qiu Y, Huang X, et al. Survivin is highly expressed in CD34(+)38(-) leukemic stem/progenitor cells and predicts poor clinical outcomes in AML. Blood. 2012;120(1):173-180.

114. Small S, Keerthivasan G, Huang Z, Gurbuxani S, Crispino JD. Overexpression of survivin initiates hematologic malignancies in vivo. Leukemia. 2010;24(11):1920-1926.

115. Kumar B, Yadav A, Lang JC, et al. YM155 reverses cisplatin resistance in head and neck cancer by decreasing cytoplasmic survivin levels. Mol Cancer Ther. 2012;11(9):1988-1998.

116. Bernardo PS, Reis FR, Maia RC. Imatinib increases apoptosis index through modulation of survivin subcellular localization in the blast phase of CML cells. Leuk Res. 2012;36(12):1510-1516.

117. Qin Q, Zhang C, Zhu H, et al. Association between survivin $-31 \mathrm{G}>\mathrm{C}$ polymorphism and cancer risk: meta-analysis of 29 studies. J Cancer Res Clin Oncol. 2014;140(2):179-188.

118. Radojevic-Skodric S, Basta-Jovanovic G, Brasanac D, et al. Survivin gene promoter $-31 \mathrm{G} / \mathrm{C}$ polymorphism is associated with Wilms tumor susceptibility in Serbian children. J Pediatr Hematol Oncol. 2012;34(8):e310-e314

119. Li F, Yang J, Ramnath N, Javle MM, Tan D. Nuclear or cytoplasmic expression of survivin: what is the significance? Int J Cancer. 2005; 114(4):509-512.

\section{Dovepress}

and the Elsevier Bibliographic databases. The manuscript management system is completely online and includes a very quick and fair peerreview system, which is all easy to use. Visit http://www.dovepress. $\mathrm{com} /$ testimonials.php to read real quotes from published authors. 